\title{
A fenomenologia dos corpos que não devem produzir desejo
}

\author{
Vitor Gomes' (iD) 0000-0003-3388-1054 \\ Andressa Mafezoni Caetano' (ii) 0000-0003-0944-2596 \\ Hiran Pinel ${ }^{2}$ (iD) 0000-0002-8540-6653 \\ 'Universidade Federal do Espírito Santo, Centro de Educação, Programa de Pós- \\ Graduação de Mestrado Profissionalizante em Educaçãa, Vitória, ES, Brasil. 29075-910. \\ ${ }^{2}$ Universidade Federal do Espírito Santo, Centro de Educação, Programa de Pós- \\ Graduação em Educação, Vitória, ES, Brasil. 29075-910
}

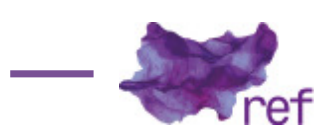

Resumo: Trata-se de artigo com inspiração teórica fenomenológico-existencial. Pretende desvelar sentidos/sentidos acerca do corpo que não deve produzir desejo, do corpo com paralisia cerebral, a partir do afloramento sexual da personagem Gabriela Brimmer, do filme Gaby, uma história verdadeira. Como metodologia, utiliza instrumentos da pesquisa fenomenológica como descrição e versão do sentido. Como resultado, mostra que a produção desvela o protagonismo da moça, que evidencia corpo paralisado, mas não imóvel, não silenciado de ânsias, quebrando o paradigma da pessoa com paralisia cerebral como eterna infante, assexuada e, por isso, destituída de desejos. Como considerações finais, desvela que abafar o desejo sexual significa emudecer desejos vitais, que perpassam as existências.

Palavras-chave: corpo paralisado; sexualidade; inspiração fenomenológica.

The Phenomenology of bodies that should not produce desire

Abstract: It is an article, with theoretical inspiration in existential phenomenology. It intends to reveal senses/senses about the body which must not produce desire, from the body with cerebral palsy, from the sexual arousal of the Gabriela Brimmer character, from the film Gaby, a true story. As methodology, it uses tools from the from the phenomenological research such as description and version of the sense. As result, it shows that the production reveals the protagonism of the girl, who has a paralyzed body, but not immobile, not silenced by craving, breaking the paradigm of the person with cerebral palsy as an eternal infant, asexual and, thus destitute of desires. As a conclusion, it points out that stifling sexual desire means silencing vital desires, which permeate existences.

Keywords: Paralyzed body; Sexuality; Phenomenological inspiration.

\section{Introdução}

Uma mulher com um corpo escultural caminha até a grade alicerçada sobre o chão. Nesse momento, a bolsa de ar frio advinda da passagem subterrânea do metrô levanta sua saia. Dirigindose ao seu acompanhante, expressa: "Não é uma delícia?". Com olhos envoltos de desejo e fitando seu corpo, o homem concorda: "Refresca os tornozelos, não é?". Trata-se da cena icônica de O pecado mora ao lado (1955), filme dirigido por Billy Wilder e protagonizado por Marilyn Monroe.

Desde então, falar de sexo pela via do cinema é visto como possibilidade de discutir questões relacionadas a tabus da sociedade, cabendo a alguns diretores mais audaciosos, sobretudo os do cinema popular/comercial, desvelá-lo com novas abordagens que auxiliam no rompimento de barreiras de censura e repressão para sua gradual e futura apresentação clara e objetiva (Guacira LOURO, 2000, p. 3). 
Nessa perspectiva, é necessário relembrar, com intuito meramente ilustrativo, alguns precursores e seus filmes, entre os quais Rui Guerra, de Os cafajestes (Brasil, 1962); Bernardo Bertolucci, de O último tango em Paris (França/ltália, 1973); Tinto Brass e Bob Guccione, de Calígula (Itália, 1979), e outros que se destacaram no enfrentamento de tabus, seja da nudez, seja da/do sexualidade/sexo, seja das/dos personagens históricas/históricos sem pudor. Com a audácia dos pioneiros, o sexo passou a ser abordado de maneira menos restritiva, sendo interiorizado (até certo ponto) com 'naturalidade' pelo público em geral. Polêmicas à parte, cristalizou-se nas tramas em que sua aparição tornava crível a realidade de seus personagens como sujeitos de carne e osso.

Quer pelo jogo em preto e branco (implícito), quer por sua gradual apresentação ao vivo e em cores, o ato sexual é exibido (e vivenciado) ao espectador como num jogo de tabuleiro em que as peças adicionadas instigam o conflito entre o anseio (instinto) e a repressão (valores ético-culturais internalizados). Dessa forma, estabelece-se o paradoxo entre o "querer" e o "não poder", pela pulsão de desejo e autorrepressão, pelo confronto entre o id e o superego (Sigmund FREUD, 1980). Essas são questões de cunho psicanalítico cujo caminho não se pretende percorrer neste artigo.

Ainda que as histórias gradualmente envolvessem o ato sexual como fragmento de sua composição, havia escolhas entre qual/quais o/os corpo/s seria/seriam apresentado/s. Por essa via, envolviam as relações sexuais entre personagens dentro da imagética do que era considerado como beleza/perfeição física. Eram corpos musculosos, cheios de curvas, simetrias, apresentados como objeto de desejo ao espectador que ansiava em ser e/ou possuir tal característica.

Assim, versar cinematograficamente sobre os desejos do corpo que não é capaz de produzir desejo se constitui, até os dias atuais, como terreno selvagem, no qual poucos diretores se propõem/ propuseram a avançar. Ainda para ilustrar algumas produções que abordam a temática, destacamos Ben Lewin, de As sessões (EUA/2012); Damien O'Donnell, de Os melhores dias de nossas vidas (Reino Unido, 2004); Carlos Brooks, de Quid pro quo (EUA, 2008); Kyong-duk Cho, de Voluntária sexual (Coréia do Sul, 2008); Geoffrey Enthoven, de Venha como você é (Bélgica, 2012); Thea Sarrock, de Como eu era antes de você (Reino Unido, 2016), que, de forma direta e/ou implícita, destacaram e sublinharam em seus filmes corpos deficientes/paralisados imersos pelo desejo sexual.

E que corpo é esse que não deve produzir desejo? Trata-se de uma alegoria utilizada por nós como referência ao corpo cuja imagética social não os apresenta como desejáveis, Nesse sentido, poder-se-iam citar corpos que evidenciam deficiências físicas, paralisias e/ou outra particularidade que não os caracterizem sócio-historicamente por instigar a outro(s) sexualmente.

Para fins de compreensão desse fenômeno, lançaremos mão do filme Gaby, uma história verdadeira (1987), dirigido por Luis Madoki, uma coprodução entre os Estados Unidos e o México, cuja imersão existencial (Yolanda FORGHIERI, 1993, p. 60) fez emergir o título deste artigo.

Nesse sentido, voltaremos no tempo, exatamente há trinta anos, quando esse assunto era praticamente ignorado pelo cinema. Na época, a produção avançou na discussão sobre a temática sexualidade e deficiência, apresentando uma história baseada em fatos da vida de Gabriela Brimmer. O filme abriu possibilidades de discutir as questões que atravessam a sexualidade das pessoas, independentemente de sua condição física e, assim, evidenciando-as como corpo composto de sexualidade e desejos carnais.

A história de Gaby nos instiga a refletir acerca da sexualidade a partir de um corpo que deve ser calado, sufocado, assexuado e infantilizado (Lígia AMARAL, 1994, p. 77), que não deve produzir desejo no outro e nem deve desejar, numa relação na qual o olhar social, personificado por uma pretensa 'normalidade', rotula, escolhe e define quais sujeitos devem ou não ter e satisfazer seus desejos. Trata-se de um padrão social que produz a heteronomia em certos corpos/indivíduos.

Este artigo, que tem inspiração fenomenológica existencial, pretende realizar uma 'leitura' sobre esse corpo e sua relação entre a descoberta/a realização do desejo sexual da personagem Gabriela e sua afirmação como 'eu feminino' sexualizado para além de fragmentos limitadores impressos pela paralisia física. Nessa esteira, enseja desvelar sentidos/sentidos diante do que essencialmente é dito, sentido e internalizado dessa experiência cinematográfica.

\section{Lentes da fenomenologia}

A principal característica das pesquisas fenomenológicas é a opção de "ir às coisas mesmas" (Maria Aparecida BICUDO, 2000, p. 72), procurando identificá-las da forma como elas se apresentam para o sujeito intencional, transcendendo seus contornos, num movimento de compreensão de suas essências (Carlos FRANÇA, 1989; Daniel Augusto MOREIRA, 2002) não no sentido de imobilidade, mas de como se apresentam num espaço-tempo. A essência, dentro da visão existencialista deste trabalho, é o mais profundo que podemos compreender dentro dos limites de nossa percepção.

As pesquisas fenomenológicas baseiam-se em momentos simbólicos que significam atitudes de distanciamento e aproximação envolvendo processos perceptivos e suas posteriores associações teórico-científicas (FORGHIERI, 1993). Autores como Bicudo (2000), França (1989) e Moreira (2002) 
consideram que a pesquisa fenomenológica se constitui de momentos que envolvem a colocação do fenômeno em suspensão, separando-o de suas influências externas (destaque); sendo sucedida de sua análise conforme vivências e imbricações teóricas/científicas/vivenciais (desvelamento).

Em nosso entendimento, a escolha do método de pesquisa está ligada a dois aspectos fundamentais. O primeiro se refere à sua compatibilidade com o que é pretendido no estudo. Nesse sentido, quando o intuito é a intervenção direta para transformação da realidade, é necessária a escolha de procedimentos e modalidades de pesquisa que possuam características ativistas favorecendo tal objetivo. Da mesma forma deve acontecer quando o propósito é o inverso, por exemplo, a descrição e a compreensão de aspectos referentes ao indivíduo ou grupo, para o seu exclusivo desvelamento e compreensão.

O segundo aspecto diz respeito às "lentes" para captura do que se pretende evidenciar. Por essa via, a escolha pela fenomenologia como inspiração neste artigo se deu com suporte em sua possibilidade de imersão qualificada dentro do fenômeno, tendo em vista as concepções e os instrumentos que a constituem como favorecedoras ao discernimento e à captura da realidade. Assim, trata-se dos óculos simbólicos utilizados para apreensão de contextos, bem como para valorização dos processos perceptivos que antecedem e acompanham a sua observação.

Maurice Merleau-Ponty (201 1), no prefácio de A fenomenologia da percepção, afirma:

A fenomenologia é o estudo das essências; e todos os problemas, segundo ela, voltam a definir as essências: a essência da percepção, a essência da consciência, por exemplo. Mas a fenomenologia é também uma filosofia que recoloca a essência na existência, e não pensa que se possa compreender o homem e o mundo de outra forma, que não seja a partir de sua facticidade (p. 1).

Neste artigo, voltamo-nos para a essência eidética, fundamentada na vivência e no impacto de um filme cuja imersão compreensiva se dá a contar da utilização de instrumentos/práticas comuns às pesquisas fenomenológicas. Dessa forma, realizamos uma pesquisa com inspiração fenomenológica com base em nossos vieses existenciais, sem, entretanto, abdicar de práticas como o envolvimento existencial e o distanciamento reflexivo (FORGHIERI, 1993, p. 60).

Para Moreira (2002), o método fenomenológico, apesar de único, admite variantes diversas. Já Virginia Moreira (2004) evidencia que "[...] existem várias, e não uma única fenomenologia" (p. 447). Partindo dessa(s) premissa(s), seja como variante, seja como realização de uma fenomenologia singular, o leitor poderá perceber aproximações com concepções que emergem segundo nossos sentidos intersubjetivos.

Citando Merleau-Ponty, Rosana Azevedo e Regina Lopes (2010) defendem que

[...] todo conhecimento presente em nossa consciência passa, previamente, pela percepção. Sua filosofia também pode ser definida como 'filosofia do corpo', pois é através e a partir dele que se estabelece a existência humana no mundo (p. 1068).

Assim, entendemos que toda pesquisa traz consigo também a compleição teórica/ conceitual/vivencial/perceptiva de quem a realiza; portanto, é a expressão do sentido/sentido do pesquisador, o sentido particular de interpretação em relação aos dados dentro de sua percepção da realidade (Mauro AMATUZZI, 2009).

Importante ressaltar que pesquisas fenomenológicas são envoltas em concepções e atitudes não diretivas para a compreensão dos fenômenos. Destarte, quanto menor a diretividade, melhor será a compreensão/o desvelamento do que se observa. Por isso, como sujeitos imbricados, compreendemos que o papel do/a fenomenólogo/a é reduzir ao máximo a interferência dos apriorismos segundo comportamentos que não influenciem o fenômeno observado.

Apresentados os aspectos teóricos da fenomenologia e que envolvem sua concepção metodológica, é necessária a indicação dos instrumentos de pesquisa utilizados para coleta, análise e interpretação dos dados. Para isso, utilizamos três momentos:

a) descrição: transcrevemos cenas do filme, sem realização de observações e executando sua exclusiva descrição. O intuito desse procedimento, como instrumento para coleta de dados, foi a tentativa de suspensão do fenômeno (epoché), na medida em que, na fruição do filme, os pesquisadores se restringiram ao seu registro literal, utilizando-o como instrumento para descrição do vivenciado;

b) leitura dos registros: destacamos/sublinhamos as vivências do afloramento sexual e preconceito, fundadas na perspectiva de um corpo que não deveria sentir/produzir desejo. Após tal vivência, o enfoque da questão da sexualidade da personagem protagonista ocorreu com a leitura dos registros e o destaque dessas unidades de significado;

c) versão do sentido: refere-se aos relatos registrados após a fruição posterior de trechos do filme que abordam especificamente questões das vivências da personagem, das quais foram produzidas reflexões segundo percepção e sentidos/sentidos de seus pesquisadores.

No que se refere aos intuitos, aos procedimentos e às concepções, este artigo foi constituído com fundamento na pesquisa fenomenológica eidética, cuja característica é o desejo de 
elucidação do vivido (Adriano HOLANDA, 2003) que, nesse caso, é alimentado pela força motriz do impacto imagético/cinematográfico do filme citado, cujo percurso metodológico se baseia na percepção que ensejou o desnudamento da personagem Gaby, no que se refere à descoberta e à realização do desejo sexual.

\section{Gaby!}

O filme Gaby: uma história verdadeira apresenta a biografia de Gabriela Brimmer, mulher com paralisia cerebral, vista pelos pais e pela sociedade como expressão de corpo incapaz. 0 desenvolvimento cognitivo e expressional da personagem se inicia com a chegada de Florência, contratada para ser sua cuidadora na infância.

Numa atitude inclusiva e visionária, a funcionária inicia sua interação com a criança com uma série de estímulos sensórios-interacionais, o que resulta, a partir daí, no desenvolvimento de seus processos comunicativos por meio do seu pé esquerdo, a princípio com prancha de comunicação (tábua com letras do alfabeto) e, posteriormente, com uma máquina de escrever. Essa mudança em lidar com o corpo dito 'incapaz' possibilita a escolarização da personagem por meio de seu ingresso numa instituição especializada.

Gaby, como era chamada, era filha de europeus refugiados no México que quando pequena, seus pais a levaram incessantemente a diversos médicos, mas fatigados de respostas negativas decidiram aceitá-la como era, reconheceram que ela tinha um problema e optaram por seguir normalmente. Ela possuía um distúrbio neurológico que a impedia de controlar seu corpo, não conseguia falar e apenas movimentava seu pé esquerdo (Jéssica ANDRADE, 2009, p. 1).

Em sua estadia na instituição, conhece Fernando, rapaz cadeirante com comprometimento cognitivo. Embora totalmente controlado pela mãe, é com ele que Gaby tem um relacionamento amoroso que gera sua primeira experiência sexual com o outro.

Numa das cenas, em atitude sensitiva de satisfação erótica, Gaby está sozinha em seu quarto, tocando sua perna direita com os dedos de seu pé esquerdo. Em meio a isso, é observada por Florência com olhar e expressão que evidenciam desaprovação e medo. Em outro take, o despertar da sexualidade se manifesta quando a moça toca Fernando com seu pé, gesto sucedido pela troca de carícias, olhares e sorrisos. Consuma-se a realização do desejo sexual da protagonista, quando está "a sós" com ele em seu quarto, onde, além de cadeiras de rodas próximas, os corpos estão em proximidade.

Fernando acaricia os seios de Gaby e retira sua roupa aos poucos, enquanto a moça escorrega lentamente de sua cadeira de rodas. Aqui se evidencia a expressão de momento de independência e escolha do que fazer com sua sexualidade e seus desejos: realizá-los! Florência se encontra sentada do lado de fora, observando-os pela fresta da porta. Sua expressão de preocupação e impotência indica pensar: como Gabriela poderia ser dotada de sexualidade e desejos e ainda realizá-los? Nesse momento, a mãe de Gaby chega até Florência e pergunta onde está a sua filha. Sem conseguir falar qualquer palavra, ela apenas insinua o quarto.

A progenitora abre a porta e observa os dois jovens nus, numa cena de descoberta afetiva sexual. Naquele momento, não eram nada além de homem e mulher na realização dos desejos carnais; eram corpos, não aqueles que não deviam despertar desejos, mas os que podiam proporcionar prazer mútuo.

A cena finaliza com a mãe de olhos lacrimejados, que expressam mescla entre surpresa e entendimento de sua filha como mulher. Em gesto de compreensão, ela fecha a porta, dirige-se à governanta e convida: "Vamos caminhar, Florência?". O chamado é a apresentação do entendimento de que sua filha ansiava por muito mais do que uma vida baseada em heteronomia. Gaby é um corpo desejante por vida e sexo. Dessa maneira, a mãe entende que deveria se retirar e ir caminhar com Florência, ou seja, mesmo com sentidos/corpos diferentes, tanto a filha como a mãe deveriam "caminhar", seguindo em frente.

A entrada de Gabriela na escola, ainda que se tratando de uma instituição especializada, traz a possibilidade de expressão dos seus aspectos cognitivos. Doravante, ela inicia seu entendimento de que aquele espaço e tempo não podem Ihe fornecer o que ela almeja. Assim, ela presta exame para se transferir para a escola regular. É aprovada e, dessa forma, apresenta crescimento acadêmico e pessoal. Esse acontecimento é o divisor de águas entre a personagem e Fernando, uma vez que o jovem permanece na instituição especializada e, assim, os dois não mais se encontram. Dentro das vivências na escola regular, seja pela falta de conhecimento de sua desordem neurofisiológica, seja por preconceito, os colegas de escola a veem como incapaz e apresentam comportamentos de aversão cristalizada por atitudes de deboche.

Em outra cena, Florência confere o resultado de um processo vestibular. É a aprovação de Gaby na Universidade do México. Nesse local, ela conhece Luiz que, devido à participação questionadora da protagonista nas aulas, começa a admirá-la e a tentar aproximações com a 
jovem. Percebendo a afinidade dos dois, Florência, conduzindo-a de automóvel para casa, questiona a jovem: "Você já não aprendeu o bastante com o Fernando? Você está entrando em algo muito pior. Se não parar...". Gaby liga o rádio do carro para interromper sua fala. Nesse momento, as duas entram num embate: cada vez em que a governanta começa a falar, a moça liga o aparelho. Não suportando a possibilidade de outra vivência sexual da jovem e, dessa vez, com rapaz dito 'normal', sua intérprete freia o veículo e abandona a direção.

Aqui se percebe que a senhora expressa atitudes de sufocamento em relação à Gabriela, como corpo que deve ser silenciado, que não deve produzir desejo e/ou desejar. Nesse sentido, o olhar de Florência, quando testemunha a jovem em seus interesses sexuais, exprime a manifestação de um 'sacrilégio'. Trata-se do duelo entre o corpo e as concepções sufocadoras, em que o desejo do corpo paralisado é visto como pecaminoso e (anti)natural. No entanto, a partir de uma série de perdas na vida de Gabriela, num espaço/tempo em que as duas prezam exclusivamente suas companhias, Florência, compreendendo suas atitudes sufocadoras das vivências de Gaby, possibilita tal experiência à jovem. Leva-a de madrugada ao apartamento de Luiz, toca a campainha e a deixa na porta.

Apesar de surpreso em ver a moça sozinha, Luiz a convida para entrar e inicia a leitura de um texto datilografado por ela e endereçado a ele que dizia: "Você chegou feito uma tempestade quando minha alma estava deserta... deserta de desejos. Quando quero correr, eu rastejo. Quando quero gritar, mal posso fazer um som". Luiz se mostra confuso em relação aos sentimentos que tinha por Gaby. Ele a admira como escritora brilhante que é, mas a dicotomia entre o "perfeito e o imperfeito", entre o desejo e o corpo que não deve ser desejado o surpreende. Ainda na cena, Gaby está próxima fisicamente do jovem e encosta seu pé nos genitais do rapaz, delineando seu desejo erótico-afetivo por ele.

Nesse momento, a questão do corpo incapaz, não desejante e, consequentemente, proibido, vem à tona, impedindo a realização de uma relação sexual madura que não acontece por causa das frases de Luiz: "O que devo fazer? Fazer amor com você? Te engravidar? Me perdoe, Gaby! Não quis machucá-la. Vamos procurar Florência". Após o inconformismo com a rejeição de Luiz, Gaby se manifesta, em texto que surge na tela, simulando sua digitação: "Como posso gritar, se não consigo falar? Como posso deixar de amar com a semente de uma mulher dentro de mim? Deus, se a vida é tantas coisas que eu nunca serei, me dê forças para ser o que eu sou".

O filme desvela o protagonismo de Gaby que, num paradoxo relativizador, apresenta heteronomia e o forte desejo de autonomia, evidenciando corpo paralisado, mas não imóvel, não silenciado de ânsias, mas, pelo contrário, composto por desejos sexuais e amorosos, sendo aceita e rejeitada, tal como o movimento constante da vida. O ponto alto do filme ocorre quando há quebra de paradigma da pessoa com paralisia cerebral como eterna infante, assexuada e, por isso, destituída de desejos. Assim, a película apresenta um convite à reflexão sobre autonomia, preconceito, discriminação, resiliência e sexualidade do corpo paralisado.

\section{Compreensões sobre a sexualidade a partir de Gaby}

A sexualidade dos "corpos paralisados", tendo por base as limitações motoras como as pessoas com paralisia cerebral, ainda é um tema pouco explorado, na medida em que os comportamentos e/ou movimentos são incorretamente interpretados. De acordo com Rosana Glat e Rute Freitas (1996), num dos primeiros livros publicados no Brasil sobre o tema - Sexualidade e deficiência mental: refletindo sobre o tema -, pais e professores reconhecem a curiosidade e os impulsos sexuais de seus filhos e alunos com deficiência, porém sua preocupação maior é encontrar meios para canalizar essa sexualidade.

É importante destacar que, de acordo com Glat e Freitas (1996) e Glat (1992), existe o mito de que a sexualidade da pessoa com algum tipo de deficiência é problemática por natureza e considerada patológica. Nesse sentido, tendo em vista tais apriorismos, constroem-se ideias e ações para a coerção de tais impulsos. Nessa perspectiva, na medida em que é negada a sexualidade dessas pessoas, também é reprimida a sua expressão de sentimentos e desejos, vistos do referencial de normalidade/anormalidade na ótica dos ditos 'normais'. Em nossa sociedade, temos dificuldades em lidar com questões como a sexualidade das pessoas com deficiência, pelo fato de enxergarmos os fenômenos baseados em dicotomias, ou seja, normais/ anormais, capazes/incapazes e uma lista cheia delas.

A fenomenologia traz sua contribuição para a discussão do tema, pois não enxerga esse corpo como dicotômico, mas sim como um todo. Nesse entendimento, para além das oposições, também é importante destacar como as sociedades têm construído a ideia de corpo ao longo do tempo e, portanto, não descolada da cultura.

No caso da pessoa com paralisia cerebral, como o corpo não corresponde, na maioria das vezes, ao padrão de normalidade motora e estética, ele não se adapta aos padrões reconhecidos como 'normais' pelo grupo social ao qual pertence. 
O corpo interage com o mundo e produz sentido, inserindo o ser humano em um espaço social e cultural. Ao mesmo tempo em que, com seu corpo, o indivíduo produz sentido e, também, integra a rede de sentidos do grupo social do qual faz parte. Portanto, assimila as formas de relação do corpo com o mundo impostas pelos estilos de vida e papéis assumidos ao longo da sua existência. Essas experiências externas e internamente impressas no corpo determinam as formas de sentir, perceber, aparecer, mostrar, ver e tocar. Neste sentido, igualmente tais experiências influenciam os modos de sentir, perceber, ver e tocar os seus semelhantes e demais entes não humanos, o que dificultam ou não as relações do indivíduo com o mundo (AZEVEDO; LOPES, 2010, p. 1068).

Nesse entendimento, para Sônia Weidner Maluf (2002), é necessário discutirmos as dimensões sociais e simbólicas do corpo, produzidas pelas sociedades, devido ao fato de que, muitas vezes, o corpo tem sido discutido por estudiosos da área das ciências humanas como abrigo da natureza, o que indica um ser humano genérico e não visto como produto e produtor de regras e valores sociais.

É preciso, então, construir um olhar sensível para buscar possibilidades de romper com a lógica de que o corpo não é apenas um produto, mas também produz regras e valores construídos na cultura, não se desconsiderando, nesse processo, as representações sociais do imaginário das pessoas que vivem e se constituem com base em suas vivências e, especificamente neste texto, das pessoas com corpos que não devem produzir desejos, limitando sua autonomia quando têm suas vontades decididas por outros.

Devido ao paradigma interiorizado pelos pais de Gaby, sua condição é justificativa para sua privação. Dessa forma, optando, ainda que inicialmente, pela sua manutenção em um ambiente controlado, impossibilitam que ela expresse sua sexualidade, entre outros aspectos, desautorizando suas escolhas.

As limitações e as dificuldades sexuais que a pessoa deficiente apresenta são, em parte, impostas pela deficiência. No entanto, seja a deficiência mental, física ou sensorial (auditiva e visual), estas dificuldades tornam-se problemas quando, através das relações sociais, atribui-se a elas representações inadequadas ou preconceituosas (Ana MAIA, 2001, p. 36).

Assim, não se trata de negação das dificuldades da pessoa com paralisia cerebral, mas como elas são significadas por outras pessoas que não vivem a mesma situação. Muitas vezes, são colocados obstáculos para a vivência e a experimentação em todos os níveis e, neste caso específico, no desenvolvimento da sexualidade. Trata-se da negação do outro no direito de viver seus instintos naturais, o que desvela relação de poder na qual um grupo hegemônico 'estabelece' as regras não verbalizadas de como, quem e de que forma deve ser expresso o desejo sexual (Norbert ELIAS; John SCOTSON, 2000).

Em contrapartida, a despeito dessa relação de sufocação do outro, existe também outro fator que funciona como estímulo à resistência psicológica servindo como possibilidade de contraposição às suas influências externas. Trata-se do processo de autoimagem e autoconceito, sobre o qual, apesar das influências externas, prevalecem os fatores internos e psicológicos de internalização do vivido e sua capacidade de resiliência e apropriação da realidade.

A relação que a pessoa estabelece com o próprio corpo é um elemento constitutivo e essencial da individualidade. E a ruptura desse elemento pela doença tem um significado especial [...]. $O$ corpo biológico somente pode ser percebido através de seus representantes os quais o constituem, e que é denominado de corpo psicológico. Dessa maneira, sobre o substrato formado pelo corpo anatômico, constrói-se a imagem corporal, que é, comumente, referida quando uma pessoa fala sobre o seu corpo. Sendo o corpo orgânico o alicerce onde se apoia a imagem corporal (AZEVEDO; LOPES, 2010, p. 1068).

Nesse sentido, o conceito ou o juízo que a pessoa estabelece de si própria é fundamental para a criação de sua autoimagem (Lucia MOYSÉS, 2002) e, dessa forma, para a produção do corpo que, para si, pode se desvelar como objeto de desejo pelo outro.

Esse é o momento em que se evidenciam os impactos (ou não) das influências sociais dentro da (auto)concepção e da identificação. No que se refere ao autoconceito, é necessário pensarmos que, devido à dualidade construída em nossa sociedade, diante da normalidade/ anormalidade e da capacidade/incapacidade, foi se moldando, em relação às pessoas com deficiência, uma característica peculiar, que é a de que essas pessoas se mantêm no período de infância (MAIA, 2001, p. 41). Esse modo de olhar e agir reforça, na pessoa com deficiência, a sua infantilização, o que não acontece em relação ao seu corpo e, consequentemente, ao desenvolvimento da sexualidade.

O olhar de que o corpo com deficiência não produz e não deve produzir desejos faz com que, muitas vezes, considerando-se um imaginário social equivocadamente construído, a pessoa com deficiência seja vista como "incapaz e eterna criança" (Hughes FRANÇA RIBEIRO, 2001, p. 15), o que contribui para a produção de sua imagem como assexuada e híbrida. Dessa forma, ela é 
negada em sua sexualidade. Trata-se de um embate simbólico, pois, de um lado, está o desejo, o biológico e, do outro, as convenções sociais expressas pelos conceitos e valores dos grupos hegemônicos.

Nessa relação de poder em que se destaca a pessoa com paralisia cerebral como eterna criança, certos estigmas e veredictos são impostos e a legitimam num permanente estado de heteronomia em relação à pessoa dita 'normal'. Trata-se do paradigma da dependência, que estabelece vínculos que retroalimentam comportamentos infantilizados. Assim, o outro alimenta o que deseja dela, impondo suas decisões e, nesse sentido, mantendo-a sob o seu controle e cuidados. Muitas vezes, nas relações de pais e mães de filhos com deficiências e em seus círculos sociais, esse modo de proceder existe e, assim, apesar de adultos, eles são tratados como crianças, o que denota uma correlação imersa numa perspectiva de cuidado, controle e, consequentemente, de sufocamento do desejo do outro, ainda que de forma não intencional.

Os pais, por seu lado, representam a sexualidade como 'angelical' e a estrutura infantil aparece como preponderante. Ou seja, os filhos são 'anjos', 'ingênuos', em si mesmos assexuados, mas profundamente afetivos e, portanto, passíveis de serem pervertidos pela 'selvageria' dos não deficientes. Esses pais chegam mesmo [...] a responsabilizar a instituição pelo 'despertar' da sexualidade dos filhos. A vigilância faz-se necessária e é 'legítima' (AMARAL, 1994, p. 78 [grifos da autora]).

Assim, o sufocamento da sexualidade pelos pais tem o caráter de 'controle' do outro, cristalizando a possibilidade de uma vida mais autônoma. Podemos destacar que, no processo de tornar a figura do outro como angélica, no caso da pessoa com paralisia cerebral, o mal sempre é o outro. Se, porventura, se desvela a manifestação do instinto ou de necessidades fundamentais do indivíduo, como o caso do desejo sexual, para os pais e mães esse desejo contém um caráter de quebra da ingenuidade e a culpa é atribuída aos indivíduos com quem se relaciona a pessoa com deficiência.

A vivência com a diferença é necessária e enriquecedora de sentidos para o indivíduo, bem como de compreensão da pessoa com/sem deficiência como sujeito real, não idealizado, considerado, dessa forma, não anjo ou, ainda, sujeito asséptico, mas humano, carregado de desejos e necessidades particulares à sua existência.

\section{Considerações finais}

Por meio da história de Gaby, visualizamos a apresentação de uma pessoa com paralisia cerebral, como sujeito carnal (MERLEAU-PONTY, 2011), que desvela seu desejo sexual e sua afetividade, vivenciando a rejeição e a aceitação de si num movimento contínuo e incerto. Esse movimento constitui e fundamenta o desenvolvimento da individualidade, do sentir concomitantemente particular e coletivo, mediado pelas relações humanas atravessadoras das vivências.

Portanto, é necessária a transcendência de concepções que sufocam o empoderamento do outro, para que possamos compreender os corpos paralisados para além de um fragmento específico (Márcia LUNARDI, 2004), entendendo-os como corpos que também possuem desejos e necessidades. Para que isso seja possível, é preciso superar visões infantilizadas, produtoras de dependência, para se alcançar a potencialização de consciências de uma inclusão real.

O filme nos auxilia no exercício da empatia, na medida em que desvela a vivência da diferença personificada a partir da personagem de Gabriela Brimmer como necessária e enriquecedora de sentidos para o indivíduo, bem como de sua compreensão como sujeito real. Dessa forma, a pessoa com deficiência não é nem herói, nem vilão, apenas ser humano, que tem desejos e necessidades particulares em sua existência.

Soma-se a isso o encontro entre a deficiência e o gênero feminino, que tem sido alvo de preconceitos, discriminação e violência, gerando impedimentos que têm colocado a mulher à margem dos processos sociais, privando-a, por exemplo, do acesso e da permanência à escolarização no ensino básico e superior, da ocupação de postos no mercado de trabalho, da remuneração compatível no mercado de trabalho, entre outros.

Entendemos que as mulheres, independentemente de sua condição física, têm necessidades de vida, de trabalho, sociais e sexuais, como aquelas que não vivem a condição da deficiência. Ademais, os movimentos realizados pelas mulheres têm permitido o debate sobre seus corpos e sua aceitação da maneira como são. Portanto, o filme ora analisado nos instiga a refletir sobre a situação na qual a mulher com deficiência se encontra na atualidade, por meio da exigência de um corpo feminino perfeito, ou seja, imposto pela sociedade.

Dessa maneira, é fundamental depreender que ser pessoa significa possuir anseios e inquietações. Assim, reprimir no indivíduo o que é vida nele, impossibilitando-lhe de vivências e crescimento em seus diversos aspectos existenciais, significa emudecer desejos vitais que perpassam as existências. É preciso que possamos refletir e desconstruir a destituição do corpo 
alheio, que o diminui e o inferioriza como estereótipo de anormalidade, estranheza e infantilidade e, por isso, corpo proibido. Afinal, é dessa forma que se legitimam as ações de embaçamento e emudecimento da compleição que se inicia pelo físico, mas também o transcende.

\section{Referências}

AMARAL, Lígia Assumpção. "Adolescência/deficiência: uma sexualidade adjetivada". Temas Psicol., Ribeirão Preto, v. 2, n. 2, p. 75-79, ago. 1994.

AMATUZZI, Mauro Martins. "Psicologia fenomenológica: uma aproximação teórica humanista". Estudos de Psicologia, Campinas, v. 26, n. 1, p. 93-100, jan./mar. 2009.

ANDRADE, Jéssica Gonçalves. Gaby: uma história verdadeira. Inclua-se [online], 2009. Disponível em http://incluirse.blogspot.com.br/2009/06/gaby-uma-historia-verdadeira.html. Acesso em 10/1 1/2017.

AS Sessões. Direção: Ben Lewin. Produção: Jude Levine e Stephen Nemeth. EUA: Fox Filmes, 2012. 1 DVD.

AZEVEDO, Rosana Freitas; LOPES, Regina Lucia Mendonça. "Concepção de corpo em Merleau-Ponty e mulheres mastectomizadas”. Rev. Bras. Enferm., Brasília, v. 63, n. 6, p. 1067-1070, nov./dez. 2010.

BICUDO, Maria Aparecida Viggiani. Fenomenologia: confrontos e avanços. São Paulo: Cortez, 2000.

CALÍGULA. Direção: Tinto Brass e Bob Guccione. Produção: Bob Guccione e Franco Rossellini. Itália: Cannes Distribuidora, 1979. 1 DVD.

COMO EU era antes de você. Direção: Thea Sarrock. Produção: Karen Rosenfelt, Alison Owen e Sue Baden-Powell. Reino Unido: MGM. 2016. 1 DVD.

ELIAS, Norbert; SCOTSON, John L. Os estabelecidos e os outsiders. Rio de Janeiro: Jorge Zahar, 2000.

FORGHIERI, Yolanda Cintrão. Psicologia fenomenológica: fundamentos, método e pesquisas. São Paulo: Pioneira, 1993.

FRANÇA RIBEIRO, Hugues Costa de. "Sexualidade e os portadores de deficiência mental". Rev. Bras. Educ. Espec., Marília, v. 7, n. 2, p. 11-28, maio/ago. 2001.

FRANÇA, Carlos. Psicologia fenomenológica: uma das maneiras de se fazer. Campinas: EdUnicamp, 1989.

FREUD, Sigmund. Os chistes e sua relação com o inconsciente. Rio de Janeiro: Imago, 1980.

GABY, uma história verdadeira. Direção: Luiz Mandoki. Produção: Pinchas Perry e Luis Mandoki. México/Eua: LkTelevideo, 1987. 1 Videocassete (110min), VHS, NTSC, som, legendado, colorido, Português. Disponível em https://www.youtube.com/watch?v=JSwOk92C9cs. Acesso em 10/1 1/2017.

GLAT, Rosana. "A sexualidade da pessoa com deficiência mental". Rev. Bras. Educ. Espec., Marília, v. 1, n. 1, p. 65-74, jan./abr. 1992.

GLAT, Rosana; FREITAS, Rute Cândida de. Sexualidade e deficiência mental: refletindo sobre o tema. Rio de Janeiro: 7 Letras, 1996.

HOLANDA, Adriano Furtado. "Pesquisa fenomenológica e psicologia eidética: elementos para um entendimento metodológico". In: BRUNS, Maria Alves de Toledo; HOLANDA, Adriano Furtado (Orgs.). Psicologia e fenomenologia: reflexões e perspectivas. Campinas: Alínea, 2003. p. 41-64.

LOURO, Guacira Lopes (Org.). O corpo educado: pedagogias da sexualidade. Belo Horizonte: Autêntica, 2000.

LUNARDI, Márcia Lise. "Pedagogia da diversidade: normalizar o outro e pedagogizar o estranho". In: REUNIÃO ANUAL DA ANPED, 27, 2004, Caxambu, ANPED. Anais... Caxambu: ANPED, 2004. p. 1-16.

MAIA, Ana Cláudia Bortolozzi. "Reflexões sobre a educação sexual da pessoa com deficiência". Rev. Bras. Educ. Espec., Marília, v. 7, n. 1, p. 35-46, jan./abr. 2001.

MALUF, Sônia Weidner. "Corpo e corporalidade nas culturas contemporâneas: abordagens antropológicas". Esboços: Revista do PPG História da UFSC, Florianópolis, v. 9, n. 9, p. 87-101, jan. 2002. 
MERLEAU-PONTY, Maurice. Fenomenologia da percepção. São Paulo: Martins Fontes, 2011.

MOREIRA, Daniel Augusto. O método fenomenológico na pesquisa. São Paulo: Pioneira Thomson, 2002.

MOREIRA, Virginia. "O método fenomenológico de Merleau-Ponty como ferramenta crítica na pesquisa em psicopatologia”. Psicologia: Reflexão e Crítica, Porto Alegre, v. 3, n. 17, p. 447-456, jul./set. 2004.

MOYSÉS, Lucia L. A autoestima se constrói passo a passo. São Paulo: Papirus, 2002.

O pecado mora ao lado. Direção: Billy Wilder. Produção: Charles K. Feldman e Billy Wilder. Estados Unidos da América: Chas K Feldman Group Productions; 20th Century Fox, 1955. 1 DVD.

O último tango em Paris. Direção: Bernardo Bertolucci. Produção: Alberto Grimaldi. França/ltália: MGM, 1973. 1 DVD.

OS Cafajestes. Direção: Rui Guerra. Produção: Jesse Valadão e Gerson Tavares. Brasil: Distribuidora de filme Sinos, 1962. 1 DVD.

OS melhores dias de nossas vidas. Direção: Damien O' Donnell. Produção: Catherine Thiernan, Jame Flyin, Juanita Wilson e Mark Woods. Reino Unido: Universal, 2004. 1 DVD.

QUID Pro Quo. Direção: Carlos Brooks. Produção: Midge Sanford, Sarah Pillsbury e Todd Wagner. EUA: Magnolia, 2008. 1 DVD.

VENHA como você é. Direção: Geoffrey Enthoven. Produção: Mariano Vanhoof. Bélgica: Imovision. 2012. 1 DVD.

VOLUNTÁRIA Sexual. Direção: Kyong-duk Cho. Produção: Kyong-duk Cho. Coréia do Sul: S/R.2008. 1 DVD.

Vitor Gomes (vitorgomes76@hotmail.com) é fenomenólogo. Doutor em Educação. Professor do Programa de Pós-Graduação de Mestrado Profissionalizante em Educação, Centro de Educação, Universidade Federal do Espírito Santo (PPGMPE/CE/UFES).

Andressa Mafezoni Caetano (andressamafezoni@yahoo.com.br) é doutora em Educação. Professora do Programa de Pós-Graduação de Mestrado Profissionalizante em Educação, Centro de Educação, Universidade Federal do Espírito Santo (PPGMPE/CE/UFES).

Hiran Pinel (hiranpinel@gmail.com) é doutor em Educação. Professor do Programa de PósGraduação em Educação, Centro de Educação, Universidade Federal do Espírito Santo (PPGMPE/ CE/UFES).

\section{COMO CITAR ESSE ARTIGO DE ACORDO COM AS NORMAS DA REVISTA \\ GOMES, Vitor; CAETANO, Andressa Mafezoni; PINEL, Hiran. "A fenomenologia dos corpos que não devem produzir desejo". Revista Estudos Feministas, Florianópolis, v. 28, n. 1, e54438, 2020.}

\section{CONTRIBUIÇÃO DE AUTORIA}

Vitor Gomes: Descrição do filme, elaboração de unidades de significado, pesquisa bibliográfica e resultados/ discussões.

Andressa Mafezoni Caetano: Elaboração dos aspectos metodológicos, teóricos. Participação nas discussões e na elaboração dos resultados.

Hiran Pinel: Elaboração e associação com os aspectos teóricos da fenomenologia e psicologia, participação na descrição no filme e participação nas discussões e na elaboração dos resultados.

FINANCIAMENTO

Não se aplica.

CONSENTIMENTO DE USO DE IMAGEM

Não se aplica. 
APROVAÇÃO DE COMITÊ DE ÉTICA EM PESQUISA

Não se aplica.

\section{CONFLITO DE INTERESSES}

Não se aplica.

LICENÇA DE USO

Este artigo está licenciado sob a Licença Creative Commons CC-BY Internacional. Com essa licença você pode compartilhar, adaptar, criar para qualquer fim, desde que atribua a autoria da obra.

\section{HISTORICO}

Recebido em 07/12/2017

Reapresentado em 27/03/2019

Reapresentado em 29/05/2019

Aprovado em 29/05/2019 